\title{
Results and analysis of field research in flood reservoirs in Kashkadarya region
}

\author{
Asror Yangiev $^{1 *}$, Dilmurat Adjimuradov ${ }^{1}$, Sherzod Panjiev ${ }^{1}$ and Rustam Karshiev ${ }^{2}$ \\ ${ }^{1}$ Tashkent Institute of Irrigation and Agricultural Mechanization Engineers, Tashkent, Uzbekistan \\ ${ }^{2}$ Ministry of water resources of the Republic of Uzbekistan, Tashkent, Uzbekistan
}

\begin{abstract}
The article presents field research conducted in Langar, Dehkanabad, Shurabsoy flood reservoirs in the Kashkadarya region. Many problems result from floods in the reservoirs; there are disturbances in the discharge and drainage facilities during the passage of accidental floods. At the same time, there was a large accumulation of turbid sediments in flood reservoirs. In the article, the calculations using empirical formulas for predicting the number of turbid sediments in Langar, Dehkanabad, Shurabsoy flood reservoirs up to 2025-2030 years are also presented, and it is noted that at present, their useless volumes are full of turbid sediments. Preliminary recommendations for assessing the safety of flood reservoirs have been developed.
\end{abstract}

\section{Introduction}

As a result of global climate change on our planet, the frequency of natural hazards in nature is increasing. Floods are an example of such natural phenomena. In particular, in Central Asia, including the regions of the Republic of Uzbekistan, floods and other dangerous natural phenomena have become more frequent over the past decade as a result of climate change. As a result, short-term floods lasting tens of minutes or hours damage bridges, roads, canals, fields and hydraulic structures in water and flood reservoirs. Floods are mainly caused by the accidental occurrence of accelerated precipitation. The constant flow of rivers is combined with the flow of floods, posing great dangers quickly and in the short term. Most major floods in the country occur in mountainous and foothill areas. Therefore, one of the urgent issues is to conduct field research on existing floodplains and study their technical condition and develop recommendations for reliable, safe operation. Below are data on flood reservoirs, where Field Research is carried out [1-7].

\section{Method}

In the research, statistical data on literary reviews, field survey data and theoretical processing of research results were used.

\footnotetext{
${ }^{1 *}$ Corresponding author: yangiev_asror_63@mail.ru
} 


\section{Results and Discussion}

The largest flood centers in the Kashkadarya region are the Kashkadarya, Guzardarya, Tankhozdarya, Yakkabogdarya basins, as well as streams in the mountainous areas of the region. Therefore, the reservoirs located in the basins of these rivers are often damaged by floods. It is caused by the accumulation of large amounts of sediments in the basins of water and flood reservoirs built in the river basins [8-19].

Considering the current technical condition of all hydro-technical structures in the Langar flood reservoir, the turbid volume of the basin was determined in 2011 and amounted to 2.98 million $\mathrm{m}^{3}$. At present, it is required to clarify the number of sediments in the flood reservoir. According to the data of $2011,40.5 \%$ of the reservoir is filled with silt; it is expedient to consider proposals for reconstruction based on the design of its catchment to ensure the safety of the water intake.

Considering the current technical condition of all hydraulic structures in the Dehkanabad flood reservoir, the volume of muddy sediments in the basin in 2010 amounted to $15.4 \mathrm{mln} \cdot \mathrm{m}^{3}$.

According to the observations made at the Shurabsoy flood reservoir, the volume of turbidity detected by the Batiometric Center in 2011 amounted to 1.8 million $\mathrm{m}^{3}$. Currently, the accumulation of turbid sediments continues. $90 \%$ of the useful volume of the flood reservoir was filled with turbid sediments. Clearance of the flood reservoir from muddy sediments should be considered based on calculations. It is necessary to calculate the current profit from the flood reservoir and consider the targeted use of the flood reservoir in the future, taking into account the loss of useful volume [20-28].

The following is the data on the consumption of floods in the foothills of the Kashkadarya region in 2015-2019 (Figure 1).

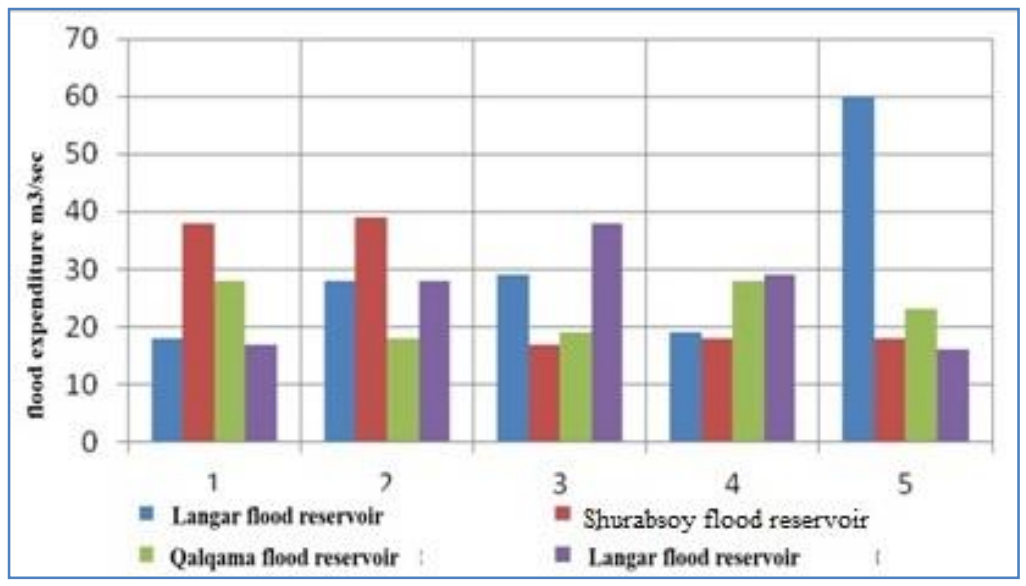

Fig. 1. Changes in maximum flood consumption during floods in the Kashkadarya river basin

Observations show that the Langar flood reservoir received 3 times more floods in 2019 than in 2018. As a result, the flood reservoir basin continues to be filled with turbid sediments. The main reason for the filling of sediments can be mainly the acceleration of floods. The current technical condition of all hydro-technical structures in the Langar flood reservoir revealed the following:

Significant damage was caused by flooding in the tract and outlets of the langar flood reservoir. (Figure 2). 

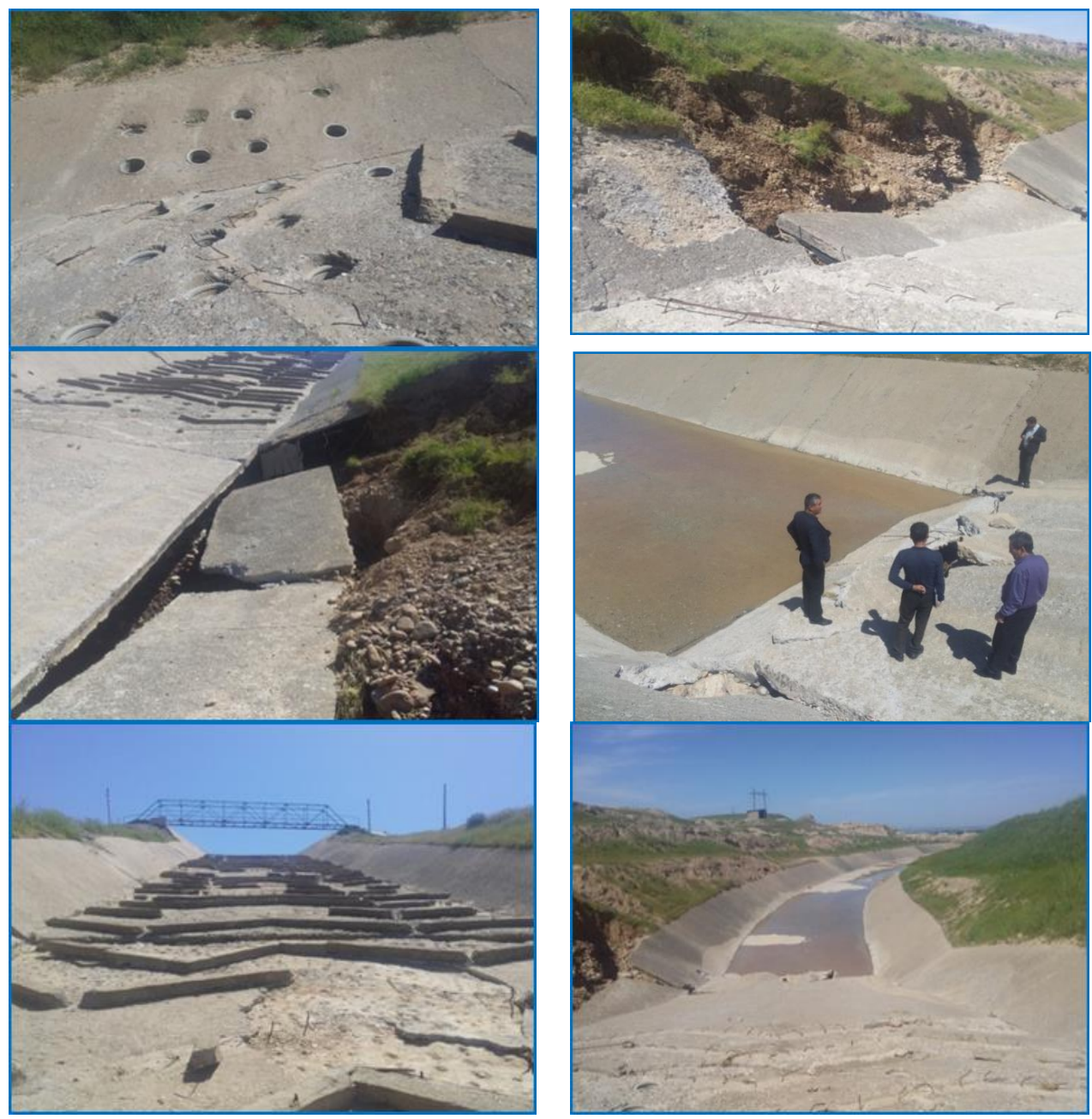

Fig 2.Damage caused by floods at the Langar flood reservoir

During the floods and their passage through the flood reservoir, the technical condition of the flood reservoir and the pumping station were negatively affected (Figure 3).

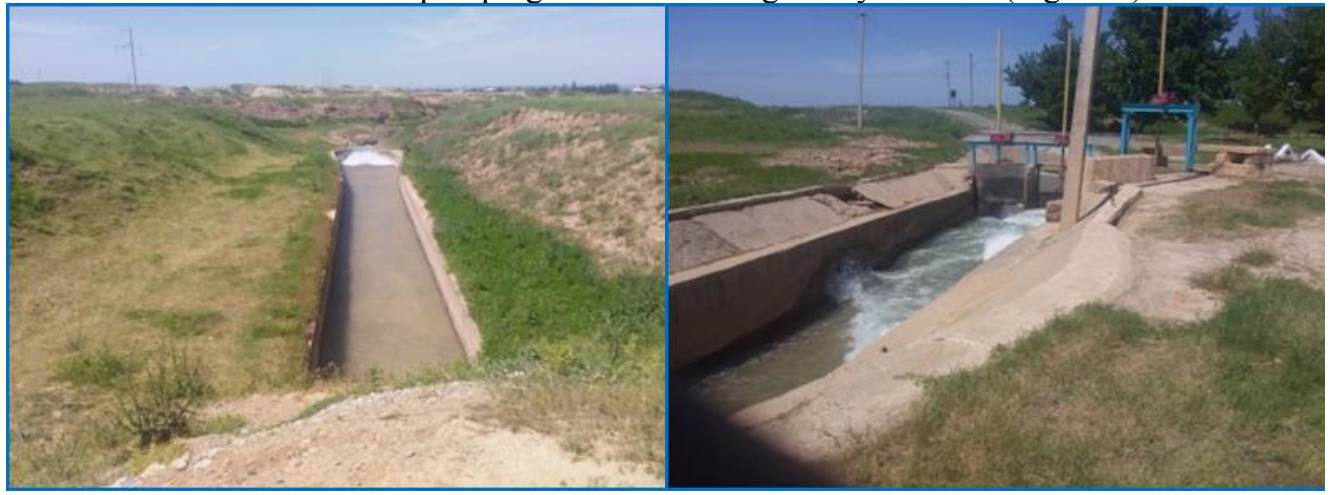




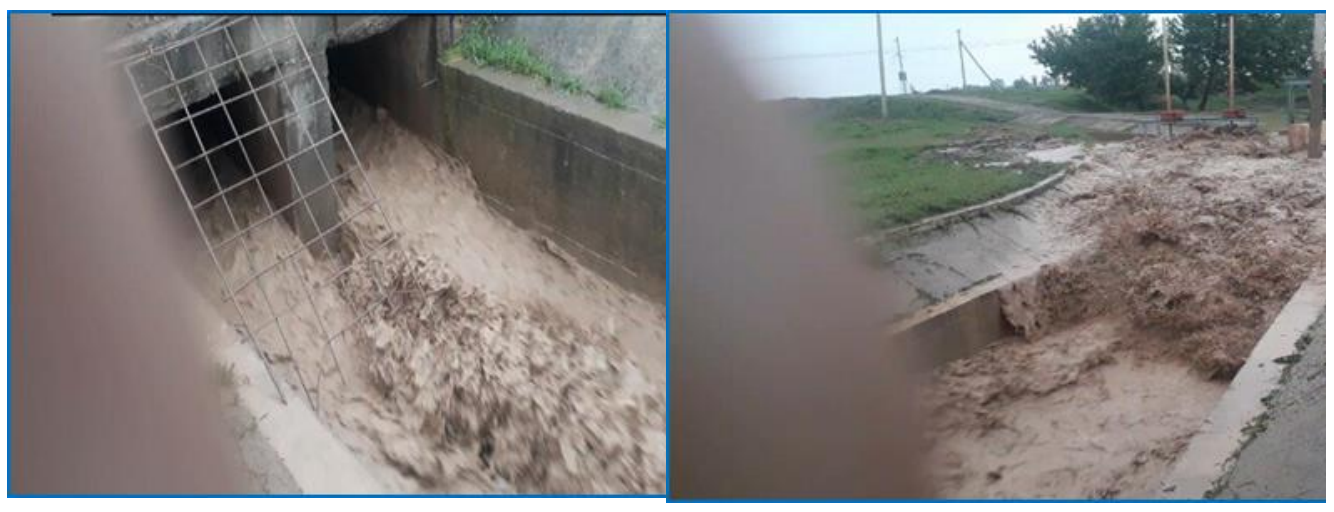

Fig. 3. Faults in the drainage structure after the flooding of the Langar flood reservoir

The results of the study of the characteristics of turbid-sedimentary deposits in the above reservoirs show that more than $90 \%$ of the solid flow consists of soils with particles $d<0.05$ $\mathrm{mm}$. Such soil particles mixed with water have a sharp effect on the physical and mechanical properties of the flow. In particular, the high viscosity and specific gravity of the flow relative to fresh water create complex hydraulic conditions in the transformation processes of floods and mudflows in the high basins. According to the observations in the flood reservoirs, the turbid stream flowing into the upper basin moves towards the dam along the deep ravine [29-36]. However, towards the dam side, the turbid flow particles are sorted and sink.

The accumulation of solid flow in the upper reaches of the flood reservoir hydropower complex is complex physical-hydraulic conditions and depends on hydrological, topographic, hydraulic, hydraulic, operational, and several other factors. Currently, there are no technically and economically effective measures to clean flood reservoirs from muddy sediments. In general, it is practically impossible to completely remove the sediments in the upper basin from the flood reservoir zone. However, if appropriate measures are not taken to reduce their amount, such hydropower plants may become completely unusable after several years [8-10].

In addition to determining the volume of turbid sedimentary deposits in the upper basin, it is important to study the characteristics of their location concerning the topographic conditions of the upper basin in solving the problem.

Parameters of turbid sediments in flood reservoirs, which have been in use for several years, differ sharply from the design calculations. According to the results of the research, the total volume of sedimentary deposits in these reservoirs can be determined as follows [4-13]:

$$
W=R^{*} n * K
$$

Here: $n$ is period of operation, year; $R$ is the perennial average amount of turbid sediments falling into the upper basin (determined based on analysis of several years of hydrological data); $K$ is wind erosion, coefficient taking into account the sediments falling from the shoreline into the reservoir $(K=1.01-1.04)$.

According to the analysis of the mechanical composition of sedimentary deposits, the average percentage by particle diameters and their weight is as follows.: $d>0.5 \mathrm{~mm}-0.1$ $\% ; d=0.25-0.5 \mathrm{~mm}-0.79 \% ; d=0.1-0.25 \mathrm{~mm}-2.33 \% ; d=0.05-0.1 \mathrm{~mm}-53.22 \% ; d=$ $0.01-0.05 \mathrm{~mm}-13.46 \%$; $d=0.005-0.1 \mathrm{~mm}-8.92 \% ; d<0.005 \mathrm{~mm}-21.18 \% ; d_{a v}=0.05$ $\mathrm{mm}[4-16]$. 
In general, the particle size of turbid sediments in the upper basins is characterized by a decrease in the direction of the dam from the entrance to the flood reservoir. In the upper storks, it is found that deposits consisting mainly of stone and sand particles are formed [17-20].

Forecasts of turbid sediments for 2025-2030 are calculated using the above empirical formula in Langar, Dehkanabad and Shurabsoy reservoirs. It can be seen that the useless volumes of the Langar, Dehkanabad and Shurabsay reservoirs are now filled with muddy sediments and will increase in the future.

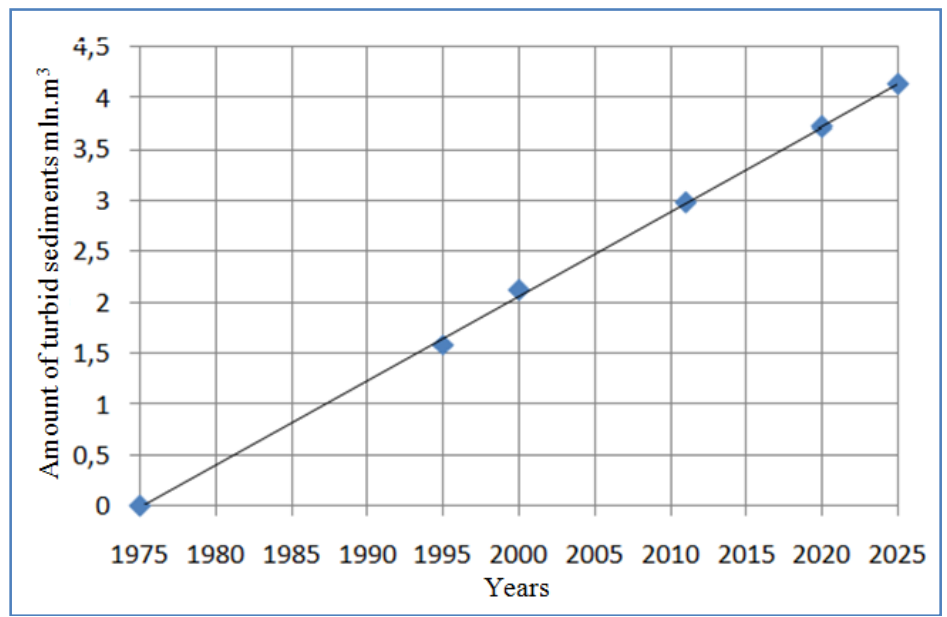

Fig. 4. Graph of change in the number of turbid sediments in the Langar flood reservoir.

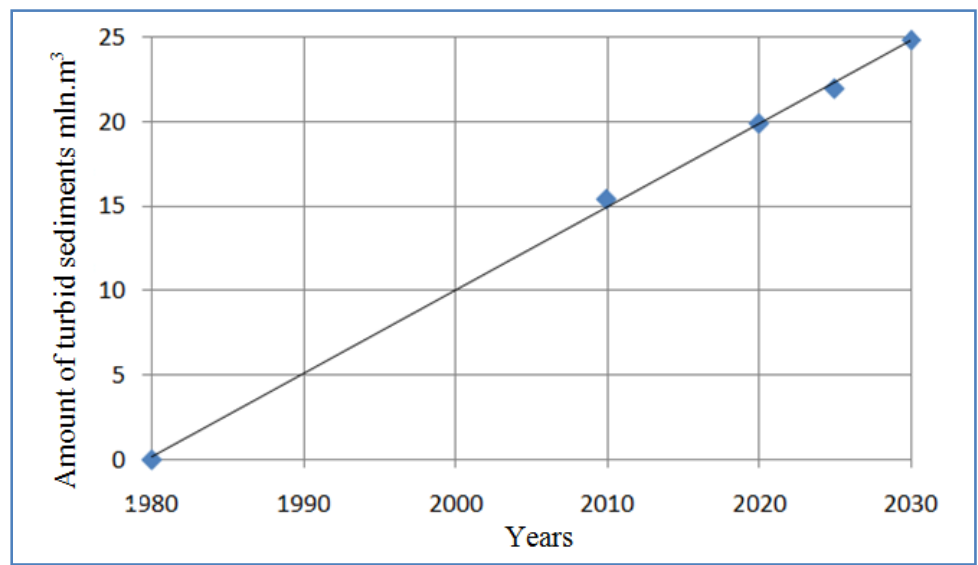

Fig. 5. Graph of change in the number of turbid sediments in the Dehkanabad flood reservoir. 


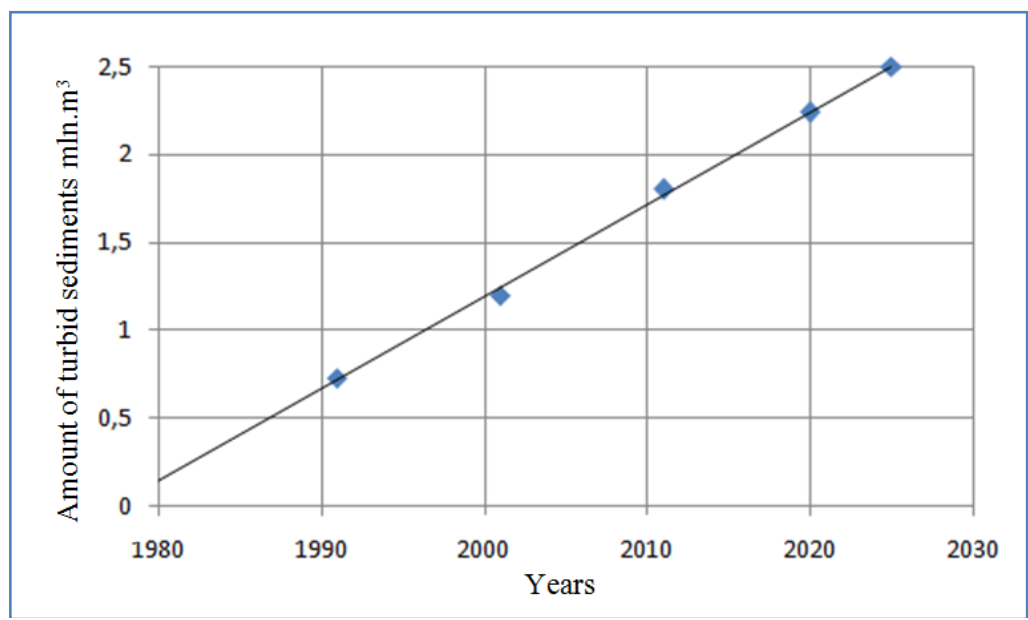

Fig. 6. Graph of change in the number of turbid sediments in the Shurabsoy flood reservoir.

Therefore, it is necessary to take constructive and operational measures to reduce the amount of sludge and remove them due to the continued field monitoring of the above reservoirs. As a result of the research, the first developed recommendations for the assessment of flood reservoirs safety were presented.

Reservoirs are considered to be in working (normal) condition (or in good technical and safe condition) when the following indicators are provided:

- the structures are capable of carrying the maximum (catastrophic) water consumption of the project, are not damaged, broken, cracked, do not sink;

- dams can withstand the water pressure (pressure) provided for in the project; the pressure slope cover is not damaged, does not swell, the pressureless slope is not damaged, there are no signs of water leakage;

- no rest (support) in the upper part, no minimum and maximum (catastrophic) water consumption in the lower and upper parts, no washing and turbid sediment sinking;

- the parts of the water supply and drainage channels are not damaged, the maximum water consumption specified in the project (without turbidity and washing of the water) is not damaged, the lining of the water supply and drainage channels is not damaged, is not broken;

- hydromechanical equipment (valves, their lifts, etc.) are not corroded, do not rot, do not deform, the joints are intact, waterproof, the lifts are lubricated and easy and fast to operate.

- In reservoirs, the following indicators are considered to be a case of reduced safety:

- dams can withstand the water pressure (pressure) provided for in the project, the pressure slope coatings or coatings at the joints are damaged, swollen, the non-pressure slope is broken, there are signs of water leakage;

- the channels of water supply and drainage channels are eroded or submerged in mud, the linings of the dams are damaged, broken, but the parts of the structures are not damaged;

- hydromechanical equipment (valves, their lifts, etc.) is slightly corroded, the seals are broken, and there is a state of water permeability; the lifts are not lubricated.

- In reservoirs, the following indicators are considered unsatisfactory safety:

- the structures are not able to carry the maximum (catastrophic) water consumption according to the project, are damaged, broken, cracked, sunk, ice, noise and debris are trapped, clogged in the drainage, drainage, drainage and drainage facilities; 
- dams can withstand the water pressure (pressure) provided for in the project; pressure slope coverings are damaged, swollen, the pressureless slope is broken, wet stain, water leakage, leakage, holes, griffin signs, corrosion of concrete parts of structures;

- in the upper and lower reaches, there is a rest (support); in the lower and upper bays, there is a state of washing and turbid drowning at the lowest and maximum (catastrophic) water flow;

- Reservoirs are a critical state of security when the following factors occur:

- the level of safety of the reservoir associated with the transition from partial disability to full disability as a result of the emergence of conditions for the development of processes that reduce the strength and durability of structures and soil, exceeding the permissible safety criteria;

- after this case, the boundary condition, which determines the depletion of the reservoir facilities in terms of inadmissibility or inexpediency of the facility following its function.

\section{Conclusions}

The results of field research in Langar, Dehkanabad, Shurabsoy flood reservoirs in the Kashkadarya region revealed the following::

1. As a result of floods in the Langar, Dehkanabad, Shurabsoy flood reservoirs, many malfunctions have been observed; disturbances have been observed in the waterthrowing and water-discharge structures while avoiding accidental floods; this is caused by the accumulation of a large number of mud sediments. Observations show that the Langar flood reservoir received 3 times more floods in 2019 than in 2018. As a result, the flood reservoir basin continues to be filled with turbid sediments.

2. According to the analysis of the mechanical composition of sedimentary deposits, the average percentage by particle diameters and their weight is as follows.: $d>0.5 \mathrm{~mm}-$ $0.1 \% ; d=0.25-0.5 \mathrm{~mm}-0.79 \% ; d=0.1-0.25 \mathrm{~mm}-2.33 \% ; d=0.05-0.1 \mathrm{~mm}-53.22 \%$; $d=0.01-0.05 \mathrm{~mm}-13.46 \% ; d=0.005-0.1 \mathrm{~mm}-8.92 \% ; d<0.005 \mathrm{~mm}-21.18 \% ; d_{a v}=$ $0.05 \mathrm{~mm}$.

3. The particle size of the muddy-sedimentary deposits in the upper basins is characterized by a decrease in the direction of the dam from the entrance to the flood reservoir. Deposits composed mainly of rock and sand particles were found in the upper storks.

4. Using empirical formulas in the Langar, Dehkanabad and Shurabsoy flood reservoirs, estimates of the number of turbid sediments for 2025-2030 were calculated. Calculations show that the useless volumes of water in the Langar, Dehkanabad and Shurabsay reservoirs are now filled with muddy sediments and will increase in the future.

5. Preliminary recommendations for the assessment of flood reservoirs safety have been developed.

\section{References}

1. Bakiev M.R., Tursunov T.N., Kaveshnikov N.T. Operation of hydraulic structures. Tashkent, (2008)

2. Law of the Republic of Uzbekistan «On the safety of hydraulic structures».

3. Malik L.K., Extreme situations, related with hydraulic structure. Hydraulic construction. № 12. pp. 1-16, (2009)

4. QXA-7-065 "Development of measures for scientifically based technical and technological modernization of water reservoirs to ensure efficient, reliable and safe 
operation” p. 98, Tashkent-(2014)

5. Muhammedov A.M. Operation of low-pressure hydro systems in rivers, transporting sediment (at the example of Central Asia). Science. p.237, Tashkent, (1976)

6. Designer is manual. Hydraulic structures. Revised by Nedriga V.P. (1983)

7. Mirihulava S.E. Reliability of hydro-melioration structures. Moscow. (1974)

8. Goldberg V.M. Relationship between underground water pollution and natural environment. Hydrometeo publ. house, Leningrad. p.248, (1987)

9. Yangiev A.A., Gapparov F.A., Adjimuratov D.S. Filtration process in earth fill dam body and its chemical effect on piezometers. E3S Web of Conferences 97, 04041 (2019) FORM-(2019)

10. Yangiev A.A., Ashrabov A., Muratov O.A. Life prediction for spillway facility sidewall. E3S Web of Conferences 97, 04041 (2019) FORM-(2019)

11. Yangiev, A.A., Bakiev, M.R., Muratov, O.A., Choriev, J.M., Djabbarova, S. Service life of hydraulic structure reinforced concrete elements according to protective layer carbonization criteria Journal of Physics: Conference Series 1425(1).

12. Yangiev, A., Eshev, S., Panjiev, S., Rakhimov, A.Calculation of sediment flow in channels taking into account passing and counter wind waves. IOP Conference Series: Materials Science and Engineering 883(1),012036 2020.

13. Choriev, J., Muratov, A., Yangiev, A., Muratov, O., Karshiev, R.Design method for reinforced concrete structure durability with the use of safety coefficient by service life period. IOP Conference Series: Materials Science and Engineering 883(1),012024 (2020)

14. Yangiev A.A. Perfection of designs, settlement substantiation and operational reliability of vertical mine spillways of highly pressure head hydro knots. p.25, Tashkent, (2016)

15. S.Eshev, Sh. Latipov, A.Qurbonov, J. Sagdiyev, M. Berdiev ,N. Mamatov. Noneroding speed of water flow of channels running in cohesive soils, IOP Conf. Series: Materials Science and Engineering 1030 (2021), doi:10.1088/1757899X/1030/1/012131.

16. Fayzullaev D.R., Hydromechanical models of movement. p.285, Tashkent, (1985)

17. VolshanikV.V., ZuykovaA.L., MordasovA.P. Theswirling flowsin hydraulic engineering structures. Energy autom. publ. house. p.230, Moscow. (1990)

18. Zuykova A.L.,Volshanik V.V. Analytical research of structure of swirling flows of a viscous incompressible fluid in a cylindrical pipe. p.155, Moscow, (2001)

19. Isakov Sh.R., Ruzmetov M.I., Khamidov A.A. Axsymmetrical problem on speed and concentration distribution in the swirling flow of a dispersed mixture. The international conference «Modern problems of mechanics» pp.36-42, Saint Petersburg, (2009)

20. Bazarov D., Vatin N., Obidov B., and Vokhidov O. Hydrodynamic effects of the flow on the slab of the stand in the presence of cavitation. IOP Conf. Ser. Mater. Sci. Eng. 1030, 012110 (2021).

21. Bazarov D., Markova I., Norkulov B. and Vokhidov O. Hydraulic aspects of the layout of head structures during water intake from lowland rivers. IOP Conf. Ser. Mater. Sci. Eng. 1015, 012041 (2021).

22. Bazarov D., Markova I., Sultanov S. and Kattakulov F. Dynamics of the hydraulic and alluvial regime of the lower reaches of the Amudarya after the commissioning of the Takhiatash and Tuyamuyun hydrosystems. IOP Conf. Ser. Mater. Sci. Eng. 1030, 012110 (2021).

23. Bazarov D. and Vokhidov O. Extinguishing Excess Flow Energy in Spillway Structures. In book: Proceedings of EECE 2020, LNCE 150, pp. 535-545, (2021) DOI: $10.1007 / 978-3-030-72404-7 \_52$ 
24. Gur'ev,A.P., Kozlov D.V., Khanov N.V., Abidov M.M., Safonova N.A. Alternative Solutions for the Energy Dissipation of Idle Discharges at the Rogun HPP, Power Technology and Engineering, 54(1), pp. 7-12, (2020)

25. Baranov E.V., Gur'yev A.P., Khanov N.V. Recommendations for Hydraulic Calculations of Anti-Erosion Lining with the Use of Spatial Geogrid with Coarse Fragmental Soil, Power Technology and Engineering, 53(5), pp. 553-556, (2020)

26. Khanov N.V., Martynov D.Y., Novichenko A.I., Lagutina N.V., Rodionova S.M. Outlook and Special Properties of Earth Anchors and Screw Piles in Burial of Modular Protection Dikes in Nonrocky Ground, Power Technology and Engineering, 52(4), pp. 405-412, (2018)

27. Kurbanov S.O., Khanov N.V. To calculation of the critical depths of the canals with polygonal profile (PP), Gidrotekhnicheskoe Stroitel'stvo, (3), pp. 42-44, (2004)

28. Kurbanov S.O., Khanov N.V. To hydraulic calculation of the most favorable sections of the power diversion canals (PDC) of a polygonal profile, Gidrotekhnicheskoe Stroitel'stvo, (7), pp. 40-43, (2003)

29. Khanov N.V. Hydraulic characteristics of chamber-free tangential vortex flow generators, Hydrotechnical Construction, 33(2), pp. 99-103, (1999)

30. Bazarov D., Markova I., Norkulov B., Isabaev K., Sapaeva M. Operational efficiency of water damless intake. IOP Conf. Ser. Mater. Sci. Eng. 869(7), 072051, (2020)

31. Anghesom A. Ghebrehiwot, Kozlov D.V. Spatial and Statistical Variability Analyses of Satellite-Based Climatic Data in Mereb-Gash Basin, Water Resources, 48(1), pp. 146-157, (2021)

32. Bednaruk S.E., Chukanov V.V., Klenov E.M., Kozlov D.V. Accounting for the Thermal State of the Sayano-Shushenskaya Dam to Determine the Safe Maximum Water Levels in the Reservoir in Developing Its Dispatch Schedules, Power Technology and Engineering, 54(4), pp. 451-455, (2020)

33. Kozlov D., Yurchenko A. The role of inspection of hydraulic structures in the assessment of their technical condition, IOP Conference Series: Materials Science and Engineering, 883(1), 012049, (2020)

34. Kozlov D., Ghebrehiwot A. Integrated design and construction approach to hydrotechnical structures in Eritrea, IOP Conference Series: Materials Science and Engineering, 869(7), 072012, (2020)

35. Kozlov D.V., Kuleshov S.L. Multidimensional Data Analysis in the Assessment of Ice-Jam Formation in River Basins, Water Resources, 46(2), pp. 152-159, (2019)

36. Khanov N.V. Vertical spillways with inclined mine and tangential for swirled. p.169, (1994) 